\title{
People with learning disabilities who have cancer: an ethnographic study
}

Irene Tuffrey-Wijne, Jane Bernal, Jane Hubert, Gary Butler and Sheila Hollins

\author{
ABSTRACT \\ Background \\ Cancer incidence among people with learning \\ disabilities is rising. There have been no published \\ studies of the needs and experiences of people with \\ learning disabilities and cancer, from their own \\ perspective.
}

Aim

To provide insight into the experiences and needs of people with learning disabilities who have cancer.

\section{Design of study}

Prospective qualitative study, using ethnographic methods.

\section{Setting}

Participants' homes, hospitals, nursing homes, and hospices in London and surrounding areas.

\section{Method}

The participants were 13 people with learning disabilities ranging from mild to severe, who had a cancer diagnosis. The main method of data collection was participant observation (over 250 hours). The median length of participation was 7 months.

\section{Results}

Participants' cancer experiences were shaped by their previous experience of life, which included deprivation, loneliness, and a lack of autonomy and power. They depended on others to negotiate contact with the outside world, including the healthcare system. This could lead to delayed cancer diagnosis and a lack of treatment options being offered. Most participants were not helped to understand their illness and its implications. Doctors did not make an assessment of capacity, but relied on carers' opinions.

\section{Conclusion}

Urgent action is warranted by findings of late diagnosis, possible discrimination around treatment options, and lack of patient involvement and assessment of capacity in decision making. There are significant gaps in knowledge and training among most health professionals, leading to disengaged services that are unaware of the physical, emotional, and practical needs of people with learning disabilities, and their carers.

\section{Keywords}

ethnography; learning disorders; mental retardation; neoplasms; qualitative research; terminal care.

\section{INTRODUCTION}

'Learning disabilities' have been defined as the presence of impaired intelligence (intelligence quotient $[\mathrm{IQ}]<70$ ) and reduced social functioning, starting before adulthood and with a lasting effect on development. ${ }^{1}$ They affect around $2.5 \%$ of the population. ${ }^{1}$ The number of people with learning disabilities in England is expected to rise steadily, partly due to reduced mortality among older adults with learning disabilities. It is estimated that the number of people with learning disabilities in England within the $\geq 50$ years age range will increase by $53 \%$ between 2001 and 2021. ${ }^{2}$ Despite these estimates, the life expectancy of people with learning disabilities remains lower that that of the rest of the population. A mortality study in 1998 found that adults with learning disabilities were 58 times more likely to die before the age of 50 years than people in the general population. ${ }^{3}$ It is recognised that this relates to inequality of access to health services as well as health problems relating to the underlying causes of their learning disabilities. ${ }^{4,5}$ The rising numbers of people with learning disabilities living into older age have been accompanied by a progressive increase in deaths from age-related conditions. ${ }^{6,7}$ The epidemiology of cancer in people

I Tuffrey-Wijne, $R N, P h D$, research fellow; J Hubert, MA, DipAnth, senior research fellow; G Butler, training and research adviser; S Hollins, FRCPsych, FRCPCH, professor of psychiatry of learning disability, St George's, Division of Mental Health, University of London, London. J Bernal, $M R C P s y c h$, consultant in developmental neuropsychiatry, Cornwall Partnership NHS Trust, Redruth, Cornwall.

Address for correspondence

Dr I Tuffrey-Wijne, St George's, University of London, Division of Mental Health, Cranmer Terrace, London SW17 0RE. E-mail: ituffrey@sgul.ac.uk

Submitted: 16 September 2008; Editor's response: 14 November 2008; final acceptance: 23 January 2009.

(c)British Journal of General Practice

This article was originally online first on 11 June 2009. Cite this article as: Br J Gen Pract 2009; 59: 503-509. Advance online publication. DOI: 10.3399/bjgp09X453413 


\section{How this fits in}

The incidence of cancer among people with learning disabilities is rising. Previous studies looked at end-of-life care for people with learning disabilities from the perspectives of social care staff and palliative care staff, but there are no reported studies of the experiences of people with learning disabilities who have cancer, from their own perspective. This study found that people with learning disabilities are at risk of delayed cancer diagnosis and possible lack of treatment options, and that there is a dearth of patient involvement in decision making and of formal assessments of capacity by physicians. Families and social care staff need significant support from health professionals, but this is often absent. People with learning disabilities benefit from routines, familiar faces, and recognition of their life story.

with learning disabilities has not been clearly established. The lack of uniform or centrally-held records of people with learning disabilities make methodologically sound studies, where comparisons can be made with the general population, extremely difficult. $^{8}$ Studies carried out in the late 1990 s suggest that cancer accounts for up to $16 \%$ of all deaths among people with learning disabilties, ${ }^{3,9,10}$ compared with $27 \%$ in the overall population of England and Wales in 2007."

Little is known about the needs of people with learning disabilities who have cancer. Some studies have looked at the end-of-life care needs from the perspectives of social care staff and palliative care staff; these found that communication problems and a lack of collaboration between health and social care agencies are barriers to effective end-of-life care. ${ }^{12-14}$ It has not been possible to find any reported studies of the cancer experiences from the perspectives of people with learning disabilities themselves.

The aim of this study was to explore the experiences and needs of people with learning disabilities who have cancer, to gain insight into their lives, the impact of cancer, the way they experienced care, and any barriers they faced in accessing health care.

\section{METHOD \\ Design}

Qualitative methods were essential, given the aim of the project, the personal nature of the material, and the range of different abilities, needs, and contexts. Ethnographic methods were used, consisting mainly of participant observation (over 250 hours in total). Participants were visited regularly, often weekly, during time frames ranging from 1 day to over 2 years (median 7 months). Participants were visited at home and in inpatient settings, and sometimes accompanied to GP and outpatient appointments. Relatives, social care staff, and medical staff were also consulted and case reviews were attended with case notes studied. The researcher's role was non-interventionist, except in cases of observing suboptimal care, where the research advisory group was consulted before intervening. The data consisted mostly of extensive field notes, written by the researcher immediately after each data-collection session.

\section{Participants}

Thirteen people with learning disabilities participated. No data were available on the participants' IQs, but it seemed that seven had mild/moderate learning disabilities (with an ability to acquire a degree of independence and to develop adequate communication skills), and six had severe/profound learning disabilities (resulting in severe limitations in communication and a need for continuous support). ${ }^{15}$ Their mean age was 53 years (range 36-66 years). All participants had a cancer diagnosis; eight had known metastases, and 10 were terminally ill. Eight participants died during the study period. At the time of diagnosis, seven participants lived in staffed residential care homes, four in their own flat, one in the parental home, and one with foster carers. The 'carer' might be a family member but was often a member of residential care staff from a social care background. In this paper, both are referred to as 'carers'.

Convenience sampling was used for the first seven participants, followed by theoretical sampling, where participants were selected on the basis of emerging concepts to be explored, and in order to ensure a wide range of contexts and experiences. ${ }^{16}$

\section{Consent issues}

Consent procedures included pictorial study information sheets that were introduced to potential participants by a trusted member of staff (usually a nurse or carer) before meeting the researcher. While some participants could give informed consent, others were unable to grasp the concept of the study. In those cases, proxy assent was sought from a main carer or relative; although there was no legal requirement and it had no standing in English law, the authors considered this to be 'best practice'. In all cases, the principle of 'process consent' was adopted, giving continuous attention to the question of whether the participant remained willing to engage with the researcher. ${ }^{17}$ None of the participants withdrew from the study. All aspects of the study were monitored by a research advisory group, which included health and social care professionals and three people with learning disabilities. In this paper, participants' names have been changed.

\section{Analysis}

The analysis was conducted following grounded theory principles. ${ }^{16}$ Data collection and analysis 
occurred concurrently, with continuous re-reading of the field notes, discussion with colleagues, and refinement of emerging themes throughout the study period. To increase validity, emerging themes were fed back into the field and, in some instances, discussed with participants and their carers. The researcher returned to some of the carers and hospital/hospice staff of participants who had died, to check out themes that had emerged later. Recruitment of new participants continued until saturation of the data was reached; the last three participants revealed no new themes.

The data were read, compared, and analysed independently along with summaries and extracts of the field notes. The analysis was cross-compared and overall agreement was reached. Nvivo 7, a software program for qualitative data analysis, was used to manage the data.

\section{RESULTS}

\section{Dependent lives}

It was not possible to understand participants' responses to cancer and its effect on their lives without exploring the impact of their life experiences, their relationships, and those aspects of life that mattered to them. Participants' lives were defined by their dependence on carers. They needed someone to negotiate contact with the outside world, and many aspects of their lives were supervised, particularly for those with moderate to profound learning disabilities. Most participants lacked the opportunities and power to make decisions that affected their lives. All participants had been vulnerable to bullying and abuse from peers and from people in authority throughout their lives, ranging from name-calling to physical, sexual, and financial abuse. They were particularly vulnerable when ill. In one case, abuse from a social care worker was observed by the researcher, where a frail, terminally ill participant was forcefully made to have a drink despite her cries of protest (the researcher reported this incident, which led to a social services investigation and disciplinary action).

\section{Cancer diagnosis and treatment decisions}

Diagnosis depended on someone other than the patient either noticing that something was wrong, or correctly interpreting sometimes persistent complaints or behavioural changes. Although comparisons with the general population cannot be made, it was striking that diagnosis was late in at least 10 participants. Four of these complained of symptoms, but carers either ignored or disbelieved the complaints, attributing them to 'attentionseeking' behaviour. Six participants, especially those who lacked verbal skills, did not complain, so their symptoms were unnoticed or misinterpreted.
An example of late diagnosis is Vincent Sweeney (47 years of age, mild learning disabilities), who lived alone. When he started complaining of shortness of breath and haemoptysis, his family had their doubts. His sister-in-law said:

'We didn't believe him at first, when he became ill. Because he likes to be ill. Always has done. He used to make up illnesses, he was at the GP and $A \& E$ [accident and emergency] all the time, with pain in his chest and things like that, and they could never find anything wrong with him.'

Mr Sweeney was diagnosed with lung cancer and died 2 and a half years later.

Another example is Lily Lamb (aged 55 years, moderate learning disabilities), who lived in a staffed residential care home. No action was taken when she started to complain of leg pain, became fatigued, and lost some mobility. After a number of months, Ms Lamb's day centre manager finally called an ambulance when Lily could no longer get up from her chair, and a diagnosis of stomach cancer with widespread bone metastases was made. She died 5 months later.

Several participants received an initial misdiagnosis from their GP. While this can happen to anybody, not just people with learning disabilities, it may be much harder for people with learning disabilities to decide that the doctor may have been wrong, and return to the GP. One participant, a 44year-old man with mild learning disabilities, remembered his visit to his GP:

I was complaining about a pain when I went to the toilet. The doctor said that it was a urine infection. So they gave me some antibiotics and that was that. Then I noticed a lump on my willie, and I just thought "it's an infection, the tablets will help it clear up". But it got worse. I just kept thinking it would get better, but all the time it was getting worse. I still did nothing, kept telling myself it would be alright. I never went back to the doctor.'

This man was finally diagnosed with penile cancer when his family noticed a lump that had grown to the size of a small melon. He died 18 months later. The urology specialists at the hospital were shocked, and said that they had never seen such an advanced case of penile cancer before.

Only one participant was helped (by her doctor) to make treatment decisions. Carers had a significant influence on treatment decisions. Medical staff mostly relied on the opinion of carers, without attempting to check the views of the actual patient. 
Sometimes, such opinion was based on carers' beliefs and emotions rather than an assessment of the participants' wishes. One support worker of a woman with severe learning disabilities said:

'What is the point of putting people through worry, and add stress? Why would she need more tests? They are talking about a scan, but why? ... If the doctors said that there was a $50 / 50$ chance of the treatments working, then I would say, forget it. Just let her be happy.'

While some participants were given apparently appropriate cancer treatment, others were not offered standard treatment options. In at least five cases this was because of an assumption by doctors, or an insistence by carers, that the person would not cope with that treatment. Three women with breast cancer had not been offered a breast reconstruction. Equally, there were four instances where carers were highly suspicious of doctors' decisions not to instigate aggressive treatments, wondering whether participants were discriminated against because of their learning disabilities. The home manager of a woman with severe learning disabilities who was in the final stages of breast cancer said:

'She has nobody to fight for her, so l've got to fight. The GP shouldn't give up on her ... Why shouldn't she get the treatments? Why are they giving up on her?'

While non-treatment decisions may well have been taken on grounds that treatment was likely to be futile and not in the patients' best interest, doctors had not explained this clearly to the carers.

None of the participants questioned their lack of options or the limited direct contact with doctors. Several factors were identified that seemed to help participants cope with investigations and treatments (Box 1).

Several GPs were highly rated by the carers; this was mostly due to perceived accessibility. One carer said:

\footnotetext{
Box 1. What helps adults with learning disabilities cope better with cancer investigations and treatment.

- Trusted family or paid carer present

Preparation for appointments

- Explanation of procedures in way that was easy to understand

Familiarity with hospital or clinic

Routines, old or new

Hospital staff sensitive to needs of person
}

'They all know him at the group practice. I can ring up and even if they are full, they will just fit him in'.

\section{Capacity and understanding}

The extent to which participants were told and helped to understand their diagnosis and prognosis was determined by carers in almost every case. A 'best interest' meeting, following an assessment by the medical team of the patient's capacity to understand information and make treatment choices, was held for only two participants. In most cases, the decision concerning the extent of explanation to participants was influenced by (a) personal opinion of the carer ('I wouldn't want to be told myself'), (b) desire to protect the person from distress ('why upset him, he is happy as he is'), and (c) lack of skill and confidence in breaking bad news or communicating with the person with learning disabilities. Such a lack of confidence was evident not only in carers who did not know how to talk about cancer and dying, but also in doctors and nurses who either did not engage with the participant, or expected family and carers to do the communicating. People with severe and profound learning disabilities did not seem to worry about what was happening to them, but for the others, the effect of not understanding was considerable anxiety.

Such anxiety was evident in Sally Burnett (45 years, moderate learning disabilities), who was diagnosed with rectal carcinoma 5 years previously. When her health deteriorated and she was admitted to a hospice for terminal care, the doctor asked Ms Burnett's stepmother how much Ms Burnett knew. The stepmother said:

'She knows she has cancer. But that is all she knows. She asks sometimes, and I tell her that this is not the same as her father's cancer [he had died 12 years ago], that it can be treated... As long as you are upbeat, she is quite happy. So if you could leave it at that, please, I would appreciate it. Just be positive, and reassure her.'

The hospice team did not challenge this, on the basis that Ms Burnett's family understood more about learning disabilities than they did. Ms Burnett was never told that she was dying. She became increasingly distressed about her weakening body, fruitlessly trying to exercise her legs as she had been told that she could go back home if her legs were stronger. She died in the hospice.

Another participant (36 years, mild learning disabilities) described her experiences in hospital:

'They talked to me, but they were using language 
that I didn't understand, and I was saying, "can you say it in an easier way", but I don't think they really understood how I was really feeling. I was crying, I was feeling really down and depressed. I didn't have a clue what was going on and I was very, very scared.'

Both primary and secondary healthcare staff had little clinical experience with people with learning disabilities, and often disregarded or misinterpreted their communication. They seemed mostly unaware, for example, of the tendency of many people with learning disabilities to acquiescence. Assessment of symptoms and imparting of essential information was particularly challenging for healthcare staff. An illustration of such difficulties is presented below (Box 2).

\section{Care provision}

Carers in residential services usually wanted to give the best possible care, but lacked experience, skill, knowledge, and confidence. For example, many did not realise the extent of pain a person was in, or (if they did) that such pain could, and should, be controlled. This was the case with Nick Ballard (56 years, severe learning disabilities), who had bladder cancer. Mr Ballard had no hearing and no speech. He started to walk with a limp and clearly indicated to the researcher that his leg was painful. His home manager said:

'I think his pain killers are OK at the moment. His pain isn't too bad. It is not really a pain that he can't bear. Nick likes a bit of attention, so he will just tell everyone about the pain. If it is really bad I will be able to tell by his face. . . I don't want to start on morphine. That will be the last thing, it will be the end. I would only give him morphine if he is in awful, awful pain.'

\section{Box 2. Example of communication difficulties.}

During a doctors' round in hospital, the doctors did not speak to or look directly at Sally Burnett (45 years of age, moderate learning disabilities) until she needed to be examined. Sally responded with 'yes' to all the doctor's questions, even when the researcher knew the true answer was 'no': Have you been sick? Have you eaten anything? Are you OK? Do you feel nauseous? Yes, yes, yes, yes. The doctor then told her, speaking quickly, that she would be able to eat again once she felt less nauseous; she should just try a little bit and see how it goes, 'is that OK?'; 'Yes', she said in strong voice, but the researcher knew that she hadn't understood it. The doctors left without saying goodbye or acknowledging her.
Supporting a dying person was new to the carers, and the process of deteriorating health and the dying process caused panic. Despite the readiness of some GPs and community palliative care teams to see the participants when asked, many carers felt reluctant to ask busy doctors for more input, and therefore had insufficient healthcare support.

The participants were helped by clear routines, and they persisted with activities they enjoyed right up to their final weeks. The loss of safe routines, treasured activities, or important (family) relationships could make their illness and dying unbearable, and they fiercely resisted any such changes, demonstrating remarkable resilience. It was possible for doctors and other health professionals in inpatient settings to become part of a safe and trusted environment, by engaging directly and warmly with the participant and becoming a 'familiar face'. However, loneliness was a feature of many participants' lives, and some became even more isolated during their final illness. Others actually became less lonely, as they were surrounded by personalised care and constant attention; one family member commented on the care given in a hospice: 'She has never been so popular in her life. She hasn't had anyone in her life who took an interest in her'.

\section{DISCUSSION}

\section{Summary of main findings and comparison with existing literature}

- This prospective qualitative study highlights the need for attention to the life stories of people with learning disabilities who have cancer, in particular regarding the aspects of life and the (family) relationships that matter to them. Patients' coping skills could be assessed and understood in the light of their life experiences.

- The failure of most doctors in this study to give people with learning disabilities clear information about diagnosis and treatment options is worth noting. The study was conducted before the Mental Capacity Act 2005 passed into English law in 2007, and before the recent General Medical Council (GMC) guidance about making investigation and treatment decisions. ${ }^{18}$ This clearly states that doctors must give patients information they want or need in a form they can understand, using additional support if necessary; and that doctors should not withhold information necessary for making decisions for the sole reason that a relative, partner, friend, or carer asks them to.

- The lack of treatment offered to some participants warrants further investigation. It was not possible 
to establish with confidence the rationale for particular treatment plans in the present study, and allegations by carers of discriminatory practice could therefore not be substantiated. However, it is worth noting that the recent independent inquiry into access to health care for people with learning disabilities confirmed the presence of discrimination, abuse, and neglect across the range of health services. ${ }^{19}$

- The current study demonstrates a lack of skill and knowledge in residential services for adults with learning disabilities, in meeting the needs of service users with cancer. It confirms findings from other studies that social care staff may be deeply committed to their clients, but find it hard to cope without support from outside agencies..$^{20,21}$ It was found that carers needed more support, both practical and emotional, from GPs and other healthcare professionals, around breaking bad news, symptom control, coping at home when the illness progressed, and preparing for death.

- Difficulties in communication have consistently been shown to be a barrier in providing health care to people with learning disabilities..$^{14,22-24}$ In this study it was observed that communication was usually via carers, who often wanted to protect the participants and thereby prevented them from receiving not only information but also emotional support from outside agencies. Families of people in the general population also often want to protect their relative from bad news, ${ }^{25}$ but most doctors are in favour of telling cancer patients the truth about dying, and communicate honestly with them. ${ }^{26}$ That did not happen for the participants in this study.

- The participants experienced anxiety and fear, of which healthcare professionals were often unaware.

\section{Strengths and limitations of this study}

The strength of this study lies in its in-depth qualitative methodology and triangulation of data, providing rich insights into the experiences of people who have little formal means of communication.

The sampling methods, which used health and social care professionals to access potential participants, resulted in an under-representation of people with learning disabilities who lack the support of these services, and of those who live with their families (as the majority does).

\section{Implications for future research and clinical practice}

The sample in this in-depth qualitative study cannot be representative, and only conceptual generalisations can be made. The following questions are offered for further quantitative study, and potential collaborators are invited to contact the lead author.

- Late diagnosis: is there a difference in the length of time between cancer diagnosis and death for people with and without learning disabilities?

- Treatment and service options: is there a measurable difference between cancer treatments and services offered to adults with and without learning disabilities?

- Capacity: to what extent are treatment choices in primary, secondary, and palliative care informed by formal assessment of capacity, and by 'best interest' meetings, where the person is shown to lack capacity? Do GP practices, hospitals, and palliative care services have policies on capacity?

This study underlines the importance of good access to cancer screening and diagnostic services programmes by people with learning disabilities. However, there are still many gaps in current knowledge, such as a lack of evidence for the efficacy of the regular health checks that are now available.

GPs need to engage with cancer patients with learning disabilities, and their carers, at an early stage, in order to meet their considerable need for practical and emotional support. Carers may need as much reassurance and explanation as the patient. Information, capacity, and consent issues need to be given serious consideration.

\section{Funding body}

This study was funded by a PBSC Project Grant of £98 135 from Cancer Research UK (C19514/A6157)

\section{Ethics committee}

Ethical approval for this study was granted by the South East Multi Centre Ethics Committee (COREC) on 24 March 2005 (05/MRE01/29)

\section{Competing interests}

The authors have stated that there are none

\section{Acknowledgements}

With thanks to the participants, their families, and health and social care professionals for engaging with the researcher at such a difficult time. We acknowledge the following organisations for providing support through membership of the Research Advisory Group: The Down's Syndrome Association, The Home Farm Trust, Macintyre Care, Macmillan Cancer Support, Merton Learning Disability Service Users, Maastricht University (the Netherlands), Trinity Hospice (Clapham), United Response.

\section{Discuss this article}

Contribute and read comments about this article on the Discussion Forum: http://www.rcgp.org.uk/bjgp-discuss

\section{REFERENCES}

1. Department of Health. Valuing people: a new strategy for learning disability for the 21st century. A white paper. London: Department of Health, 2001. http://www.archive.official-

documents.co.uk/document/cm50/5086/5086.htm (accessed $23 \mathrm{Apr}$ 2009).

2. Emerson E, Hatton C. People with learning disabilities in England. 
Lancaster: Centre for Disability Research, 2008.

3. Hollins S, Attard MT, von Fraunhofer N, et al. Mortality in people with learning disability: Risks, causes, and death certification findings in London. Dev Med Child Neurol 1998; 40(1): 50-56.

4. Disability Rights Commission. Equal treatment: closing the gap - a formal investigation into physical health inequalities experienced by people with learning disabilities and/or mental health problems. London: DRC, 2006.

5. Department of Health. Health inequalities: progress and next steps. London: Department of Health, 2008.

6. Day K, Jancar J. Mental and physical health and ageing in mental handicap: a review. J Intellect Disabil Res 1994; 38(241): 256.

7. Janicki M, Dalton A, Henderson C, Davidson P. Mortality and morbidity among older adults with intellectual disability: health services considerations. Disabil Rehabil 1999; 21(5/6): 284-294.

8. Hogg J, Tuffrey-Wijne I. Cancer and intellectual disabilities: a review of some key contextual issues. J Appl Res Intellect Disabil 2008; 21(6): 509-518.

9. Cooke LB. Cancer and learning disability. J Intellect Disabil Res 1997; 41(4): 312-316.

10. Hogg J, Northfield J, Turnbull J. Cancer and people with learning disabilities: the evidence from published studies and experiences from cancer services. Kidderminster: BILD Publications, 2001.

11. Office for National Statistics. Mortality statistics: deaths registered in 2007 (DR-07 Review of the national statistician on deaths in England and Wales 2007). Newport: Office for National Statistics, 2008.

12. Todd S. Death counts: the challenge of death and dying in learning disability services. Learning Disability Practice 2004; 7(10): 12-15.

13. Brown H, Burns S, Flynn M. Supporting people through terminal illness and death. In: The Foundation for People with Learning Disabilities. Today and tomorrow: the report of the Growing Older with Learning Disabilities Programme. London: Mental Health Foundation, 2002; 95-105.

14. Tuffrey-Wiine I, Whelton R, Curfs L, Hollins S. Palliative care provision for people with intellectual disabilities: a questionnaire survey of specialist palliative care professionals in London. Palliat Med 2008; 22(3): 281-290.

15. World Health Organization. ICD-10: The tenth revision of the International Statistical Classification of Diseases and Related Health Problems. Geneva: World Health Organization, 1992.

16. Strauss A, Corbin J. Basics of qualitative research: techniques and procedures for developing grounded theory, 2nd ed. London: Sage Publications, 1998.

17. Department of Health. Seeking consent: working with people with learning disabilities. London: Department of Health, 2001.

18. General Medical Council. Consent: patients and doctors making decisions together. London: General Medical Council, 2008.

19. Michael J. Healthcare for all: report of the independent inquiry into access to healthcare for people with learning disabilities. 2008. London: Aldrick Press, 2008.

20. Todd S. Surprised endings: the dying of people with learning disabilities in residential services. Int J Palliat Nurs 2005; 11(2): $80-82$

21. Jones A, Tuffrey-Wijne I, Bernal J, et al. Meeting the cancer information needs of people with learning disabilities: experiences of paid carers. Br J Learn Disabil 2007; 35(1): 12-18.

22. Cumella S, Martin D. Secondary healthcare for people with a learning disability. London: Department of Health, 2000.

23. Sowney M, Barr O. Equity of access to health care for people with learning disabilities: a concept analysis. J Learn Disabil 2004; 8(3): 247-265.

24. Murphy J. Perceptions of communication between people with communication disability and general practice staff. Health Expect 2006; 9(1): 49-59.

25. Noone I, Crowe M, Pillay I, O'Keefe S. Telling the truth about cancer: views of elderly patients and their relatives. Ir Med J 2000; 93(4): 104-105.

26. Seale C. Communication and awareness about death: a study of a random sample of dying people. Soc Sci Med 1991; 32(8): 943-952. 